\title{
Epidemiological Descriptive Analysis of Disease Outbreaks in 2019 in Sudan
}

\author{
Hamid H. Hussien \\ Department of Mathematics, College of Science and Arts, King Abdulaziz University, Rabigh, KSA \\ Email: hamid128@yahoo.com
}

How to cite this paper: Hussien, H.H. (2020) Epidemiological Descriptive Analysis of Disease Outbreaks in 2019 in Sudan. Open Journal of Epidemiology, 10, 419-431. https://doi.org/10.4236/ojepi.2020.104033

Received: August 12, 2020

Accepted: November 7, 2020

Published: November 10, 2020

Copyright (c) 2020 by author(s) and Scientific Research Publishing Inc. This work is licensed under the Creative Commons Attribution International License (CC BY 4.0).

http://creativecommons.org/licenses/by/4.0/

\begin{abstract}
Background: Sudan has often faced outbreaks of malaria, the life-threatening waterborne disease. In 2019, the country experienced an outbreak of six different infectious diseases, i.e., cholera, chikungunya, dengue fever, diphtheria, malaria, and Rift Valley fever. Objectives: The aim of this study was to perform an epidemiological descriptive analysis of data of these disease outbreaks to determine the spatial and temporal patterns of outbreaks and to estimate the magnitude of the diseases. Methods: The data consisted of the number of cases and deaths due to disease outbreaks of cholera, chikungunya, dengue fever, diphtheria, malaria, and Rift Valley fever. We analyzed the reports of an investigation conducted by the World Health Organization and the Federal Ministry of Health, Sudan. Descriptive statistics and case fatality rate (CFR) were used in this study. Results: The frequency of disease occurrence was as follows: cholera (344 cases), chikungunya (308 cases), dengue fever ( 4236 cases), diphtheria (105 cases), malaria (5,188,135 cases) and River Valley fever (567 cases). The CFRs for cholera, chikungunya, are diphtheria were $4.3 \%, 2.05 \%$, and $9.5 \%$, respectively. The mortality rate of malaria was 0.0013. The states most affected by outbreaks of these diseases in Sudan were the western states. Women were at a higher risk for all diseases, except River Valley fever. Conclusions: This study highlights the patterns of the outbreak of these diseases in Sudan and provides a basis for future scientific research.
\end{abstract}

\section{Keywords}

Epidemiology, Disease Outbreak, Infectious Diseases, Sudan

\section{Introduction}

In the past few decades, Sudan has experienced the most devastating infectious disease outbreaks in the continent. On September 2, 2012, Darfur, located in 
western Sudan, experienced an outbreak of yellow fever, the worst in Africa in 20 years [1]. The case fatality rate (CFR) for this disease was 32\%. In June 2005, an outbreak of a febrile disease consistent with dengue hemorrhagic fever affected Port Sudan city, located in the west of the country, with a CFR of 3.8\% [2]. In June 2004, a large hepatitis E outbreak in western Darfur resulted in 2621 cases in Mornay Displaced Persons Camp [3]. Outbreaks of Rift Valley fever were reported in central Sudan during 1973, 1976, and 1981 [4]. In September 1989, there was an outbreak of acute febrile illness in the northern province of Sudan [5]. The majority of disease outbreaks that occurred to date are of three categories based on the transmission of the disease, i.e., waterborne, vector-borne, and vaccine-preventable [6] [7]. The occurrence of these diseases is mostly attributed to the limited access to and coverage of clean drinking water, sanitation, and environmental protection as well as the low rate of immunization in the country [8]. Malaria remains endemic in the country, and severe outbreaks occurred as epidemics in 1990, 1993-1994, 1995, and 2003-2004 because of the high degree of malaria transmission [9].

In 2019, the country experienced outbreaks of six infectious diseases simultaneously (cholera, chikungunya, dengue fever, diphtheria, malaria, and Rift Valley fever). All these disease outbreaks were declared during the last 6 months of 2019 and were distinguished by the extremely high number of cases compared with those in other countries in the Eastern Mediterranean region. Although malaria is an endemic and common disease in the country, it is difficult to distinguish between the variable clinical features of malaria and other infections in outbreaks or epidemics caused by febrile diseases. This is because of a lack of laboratory resources [10]. Therefore, there is a need to understand the epidemiology of these diseases in the country. This study aimed to highlight the patterns of these disease outbreaks according to spatial and temporal characteristics as well as characteristics of the affected individuals.

\section{Material and Methods}

\subsection{Data Source}

The number of cases and deaths due to the six diseases (cholera, chikungunya, dengue fever, diphtheria, malaria, and Rift Valley fever) were recorded through data analysis of reports of the joint field investigation conducted by the World Health Organization (WHO) and the Federal Ministry of Health (FMOH), Sudan (see Figure 1). The investigation was started on Epidemiological week 33 of the year 2019 and ended on Epidemic week 11 of the year 2020. Owing to the political strikes in Sudan at the end of December 2019 and the beginning of 2020 , completeness or availability of data on malaria and cholera was insufficient. Therefore, this study was based on reports available from FMOH, Sudan, supported by the WHO reports.

CFRs were calculated for the six infection diseases. Furthermore, Descriptive statistics were used to describe and present the pattern of outbreak. 


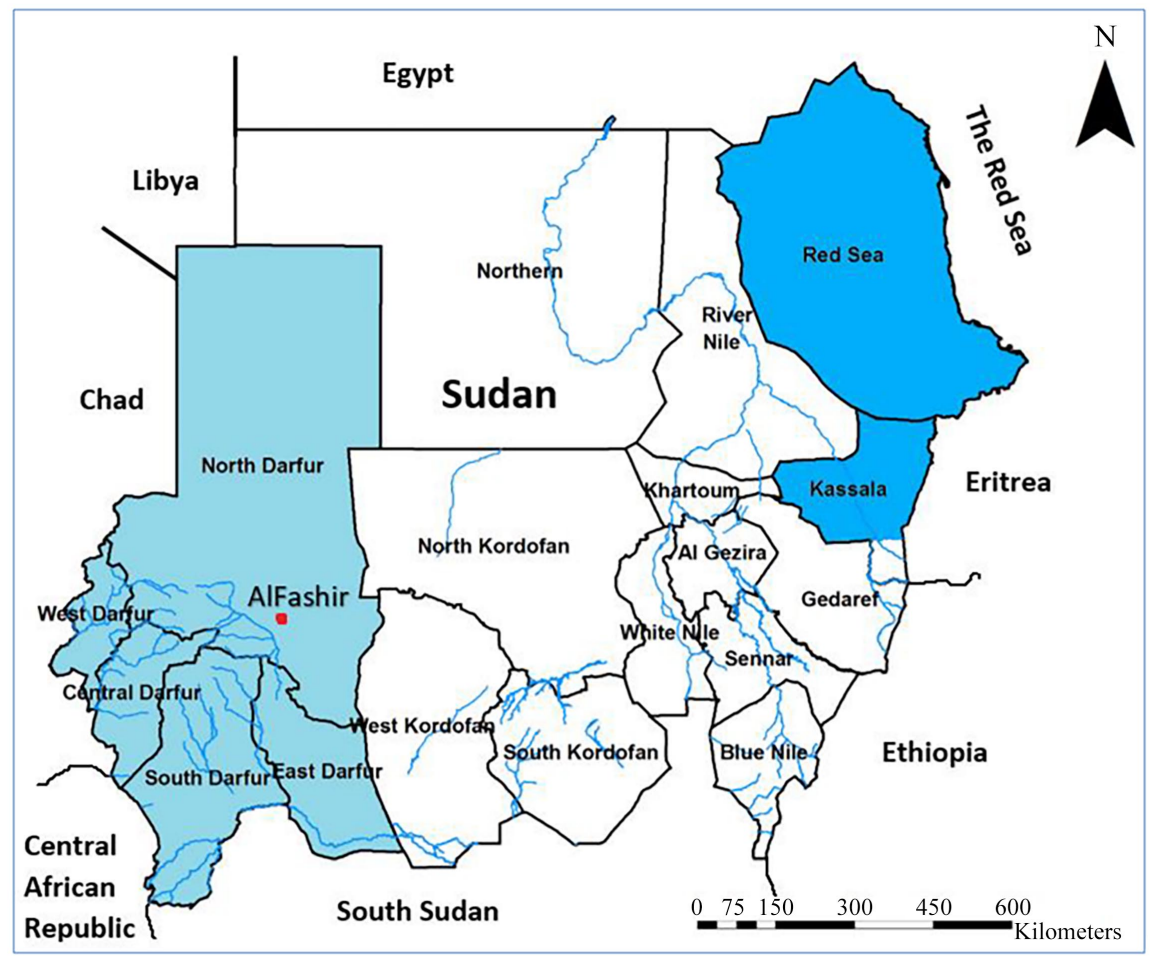

Figure 1. Map of Sudan 2019, showing the states reporting disease outbreaks. Source: https://www.mdpi.com/tropicalmed/tropicalmed-04-00043/article deploy/html/images/t ropicalmed-04-00043-g001.png.

\subsection{Epidemiological Week (epi Week)}

The epidemiological calendar divides the 365 days of the year into weeks. An epi week generally begins on Sunday and ends on Saturday. However, the first week of the year ends on the first Saturday of January (http://www.paho.org/english/sha/be v21n3-calendar.htm).

\subsection{Case Fatality Rate}

CFR is the proportion of people who die from a specific disease among all individuals diagnosed with the disease over a certain period. It is generally used to measure the severity of acute infectious diseases.

\subsection{Mortality Rate}

Mortality rate is the measure of the number of deaths in a particular population expressed in units of deaths per 1000 individuals per year. Mathematically, mortality rate is the number of deaths divided by the number of people in a particular population.

\section{Results}

\subsection{Cholera Outbreak}

Cholera outbreaks are frequent and prolonged in endemic areas with recurrent seasonal patterns. Although the disease affects all age groups, those aged $<5$ 
years are at a higher risk of contracting the disease in the endemic setting. On September 9, 2019, Sudan declared a cholera outbreak in seven localities in the states of Blue Nile and Sinnar, with 187 reported cases, including eight deaths, with a crude fatality rate of $4.3 \%$. On November 23 , the cumulative number of cases reached 338 , including 11 deaths, with a crude fatality rate of $3.3 \%$. However, owing to timely detection and prompt response, these cases remained relatively low in number compared with those in previous outbreaks. Among all age groups, the most affected age groups were $\geq 45$ years (29.3\%), followed by 15 - 30 years (26\%). Only $2 \%$ of cases were vaccinated [11]. The end of the outbreak was announced on January 23, 2020. The trend of this disease outbreak is presented in Figure 2.

\subsection{Chikungunya Outbreak}

Chikungunya fever is an arbovirus disease that is spread by the Aedes aegypti mosquito. The most common symptoms are fever and joint pain, which generally appear 3 - 7 days after a person is bitten by an infected mosquito. The disease causes acute, debilitating polyarthritis [12]. The virus is endemic in Sudan, with frequent upsurges and infections having been documented in seven states in the country [13] [14]. In 1973, the first report of chikungunya infection in Central Sudan was recorded, with a seroprevalence of 13\% [15]. On December 7, 2019, 17 new cases of chikungunya were reported in Sudan. The cumulative number of cases reached 243 , including 5 deaths ( $C F R=2.05 \%$ ). The disease spread in most of the western states in the country. The majority of cases were reported from West Darfur state (71\%). The frequent symptom in the patients was fever ( $87 \%$ of the cases) combined with joint pain and headache. The reported number of cases in the chikungunya disease outbreak is presented in $\mathrm{Ta}$ ble 1, Figure 3.

\subsection{Dengue Outbreak}

Dengue is a mosquito-borne viral infection. The virus can infect a person up to four times. Individuals became viremic at $4-6$ days after infection, which lasts for up to 12 days, with the symptom of sudden high fever $\left(40^{\circ} \mathrm{C} / 104^{\circ} \mathrm{F}\right) \mathrm{com}$ bined with two of the following symptoms: severe headache, pain behind the eyes, muscle and joint pain, nausea, vomiting, swollen glands, skin rash, and mild bleeding gums. Patients with severe dengue have a higher risk of death when the disease is not managed [16]. Dengue fever is endemic in Sudan, and several outbreaks have been documented in 2010, 2013, and 2017 [11]. This endemic disease has been considered as a major public health threat in Sudan [17]. During the past 10 years, several outbreaks have been documented in 2010, 2013, and 2017 [11].

Different parts of the country have experienced outbreaks of dengue disease; thus, this disease is associated with significant morbidity and mortality. On August 8, 2019, a dengue outbreak was officially declared in Sudan when clinical 
laboratory workers recognized an unusual increase in the number of confirmed cases of dengue fever among people living in the states of Kassala and North Darfur. Of the 77 collected samples, 31 (40\%) were confirmed to be positive for dengue. Subsequently, the disease spread to the following five states across the country: West Darfur, Red Sea, South Darfur, Gadarif, and North Kordofan. Between August 8, 2019 and October 13, 2019, the investigators documented 125 confirmed cases of dengue from Kassala state and 17 from North Darfur (See Table 1). In general, $53 \%$ of the patients were female and $47 \%$ were male, and among all age groups, the most affected age group was $<30$ years $(59 \%)$. The trend of dengue outbreak is presented in Figure 4.

Table 1. Reported cases of disease outbreaks according to sex, residence, and age, 2019.

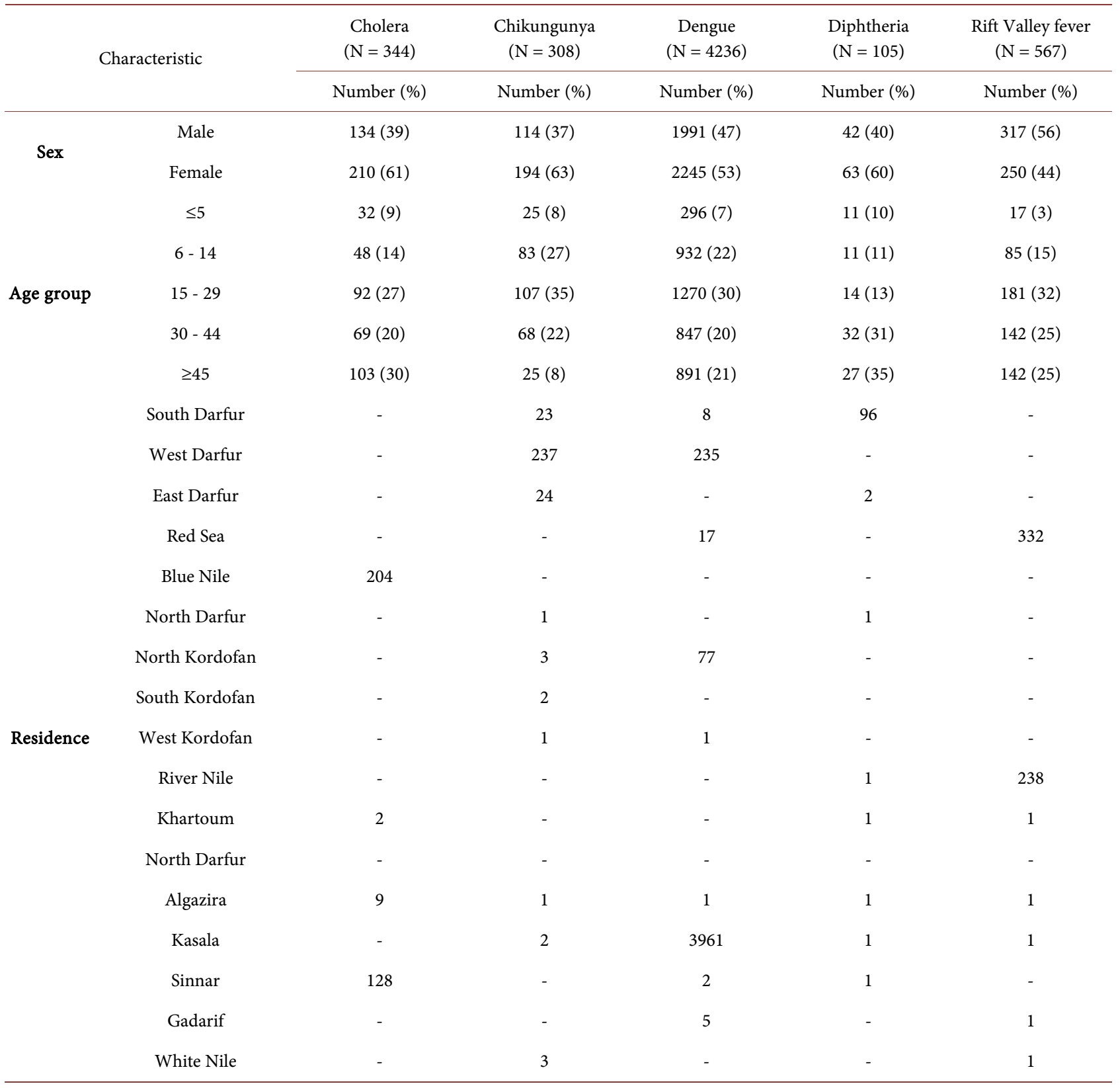




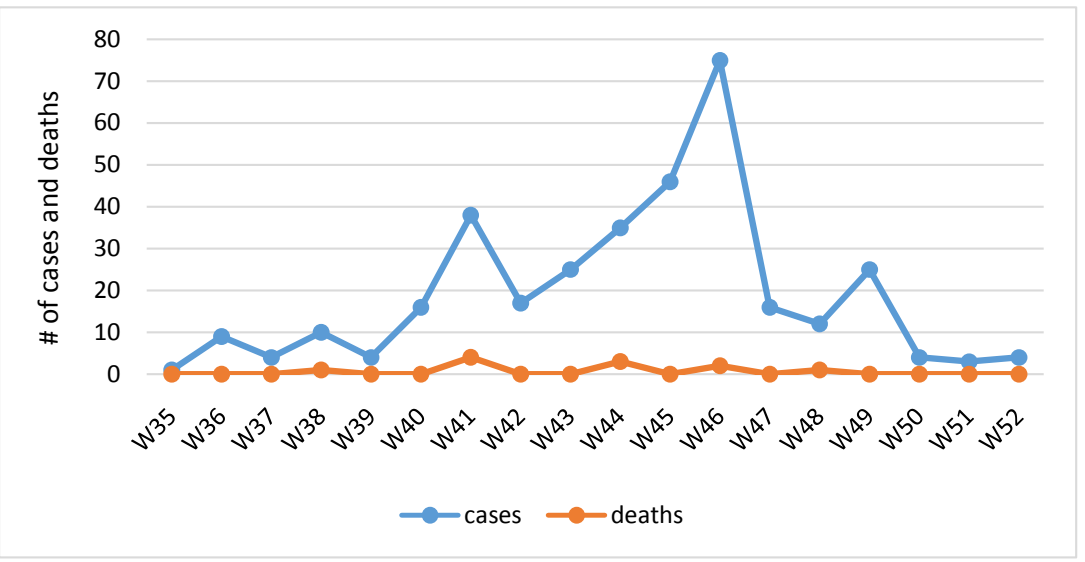

Figure 2. Cholera cases and deaths by Epi Weeks (W37-W52, 2019).

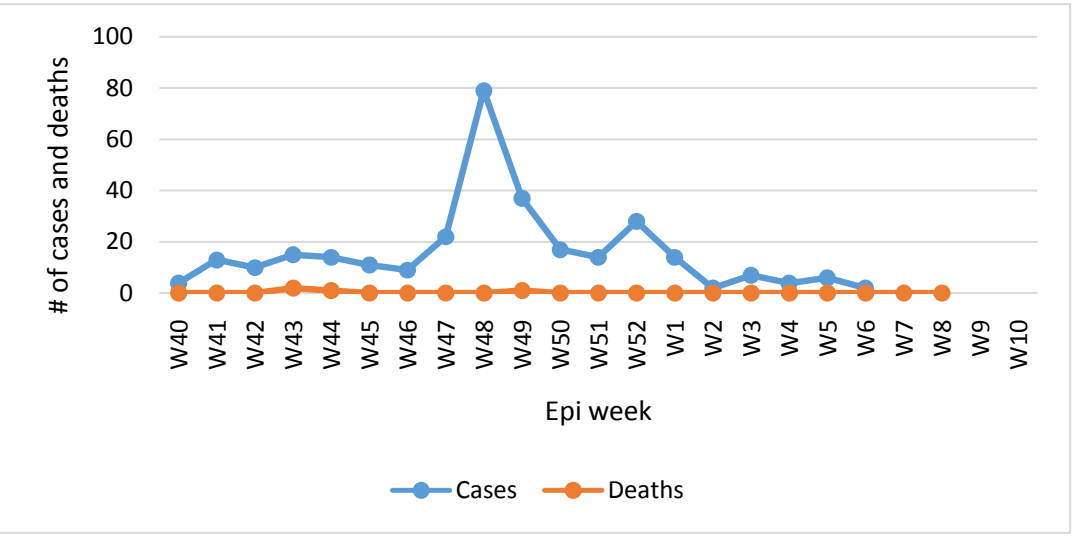

Figure 3. Chikungunya cases and deaths by Epi Weeks (W40-W52, 2019) (W1-W6, 2020).

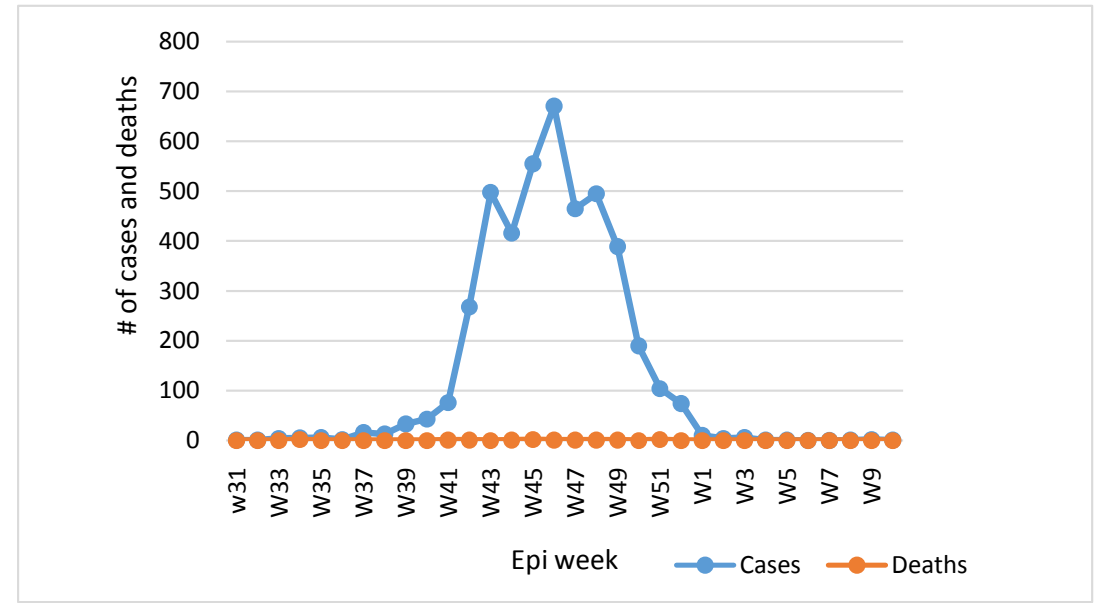

Figure 4. Dengue fever cases and deaths by Epi Weeks (W31-W52, 2019) (W1-W11, 2020).

\subsection{Diphtheria Outbreak}

Throughout history, diphtheria has been one of the most feared childhood diseases globally. It is a life-threatening contagious disease. Symptoms (sore throat 
and breathing problems) develop 2 - 5 days after infection. All age groups are at risk of developing the disease, which can be spread by an infected person's coughing, sneezing, or open wounds; however, it can be prevented with vaccination. Treatment includes antibiotics and diphtheria antitoxin [18]. From February 5, 2019, to October 31, 2019, the government reported 12 sporadic suspected cases in the states of East Darfur, North Kordofan, Khartoum, Gezira, and White Nile. In late November, the number of cases reached 98, and most cases were from South Darfur states, in particular from one locality named Al Sunta (99\%). The immunization coverage in this locality was estimated at approximately $35 \%$, which was due to the lack of mobile immunization teams (See Table 1). Up to January 2020, the number of confirmed cases from all states was 105, including 10 deaths (CFR $=9.5 \%$; Figure 5). With assistance by WHO (supplies of medicines, including paracetamol and antibiotics), the government launched an immunization campaign in the affected locality, targeting 38,881 children aged $<15$ years. The coverage during two rounds was high (80\%). By January 1, 2020, the number of new cases in all states had reduced substantially.

\subsection{Malaria Outbreak}

Malaria is a parasitic disease transmitted by mosquitos. It can be extremely dangerous if not treated promptly and properly, potentially resulting in death. The most susceptible individuals are children aged $<5$ years. The disease symptoms are fever, headache, and chills, which generally appear 10 - 15 days after an infected mosquito bites a non-immune individual.

Sudan is one of the 30 countries in the world with the highest burden of malaria. Malaria is considered endemic, with varying degrees ranging from low to high endemicity [19]. The mean reported number of malaria cases in Sudan during the period 2010-2018 was approximately 2,097,906 (95\% confidence interval [CI]: $1,126,102-3,069,710$ ), whereas the number of cases in 2018 was only 5,188,135. The number of deaths was 3129 (mortality rate $=0.06 \%$; Figure 6). Although effective treatment and prevention techniques for malaria have been available for a long time, the disease still remains a major public health problem in Sudan.

\subsection{Rift Valley Fever Outbreak}

Rift Valley fever is a mosquito-borne zoonotic disease that primarily affects animals as well as humans when exposed to the blood or organs of infected animals. The virus was first discovered in the Rift Valley of Kenya during an epidemic investigation conducted among sheep on a farm. Since then, there have been major outbreaks in Egypt (1977 and 2006); Kenya, Somalia, and Tanzania (1997-1998 and 2003); Sudan (2007); Republic of South Africa (2010); and Saudi Arabia (2000). The incubation period of the virus varies from 2 to 6 days, and no fully licensed vaccine is currently available for use outside endemic areas for animals or humans [20]. The basic symptoms of mild cases include feverish syndrome with sudden onset of flu-like fever, generalized weakness, myalgia, joint pain, and back pain. This disease is feared because of its immense econo- 
my-associated losses not only in the livestock sector but also in other related sectors [21] [22]. Being an endemic disease in Sudan, the country experienced three outbreaks of Rift Valley fever (1973, 1976, and 2008) [23]. Approximately 747 confirmed cases were reported in 2008, including 230 deaths. On September 25, 2019, the first case of Rift Valley fever was reported in the River Nile State. On November 3, 2019, approximately 319 suspected Rift Valley fever cases were reported in six states. The most affected states were River Nile (186 cases) and Red Sea (128 cases), including 11 related deaths, Kassala ( 2 cases), and Gadarif and Khartoum states ( 1 case each). Most of the affected cases were farmers (37.5\%). The outbreak curve is illustrated in Figure 7.

\section{Discussion}

This study has provided a descriptive epidemiological analysis of outbreaks of six diseases that occurred in Sudan during the second half of the year 2019, including cholera, chikungunya, dengue, diphtheria, malaria, and Rift Valley fever. The reported number of cases of disease outbreaks according to sex, residence, and age are presented in Table 1.

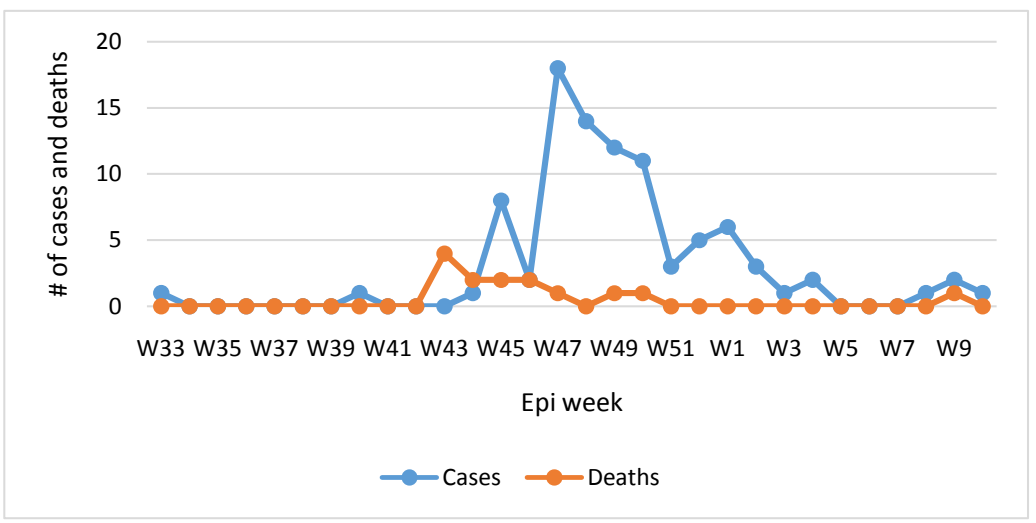

Figure 5. Diphtheria cases and deaths by Epi Weeks (W33-W52, 2019) (W1-W11, 2020).

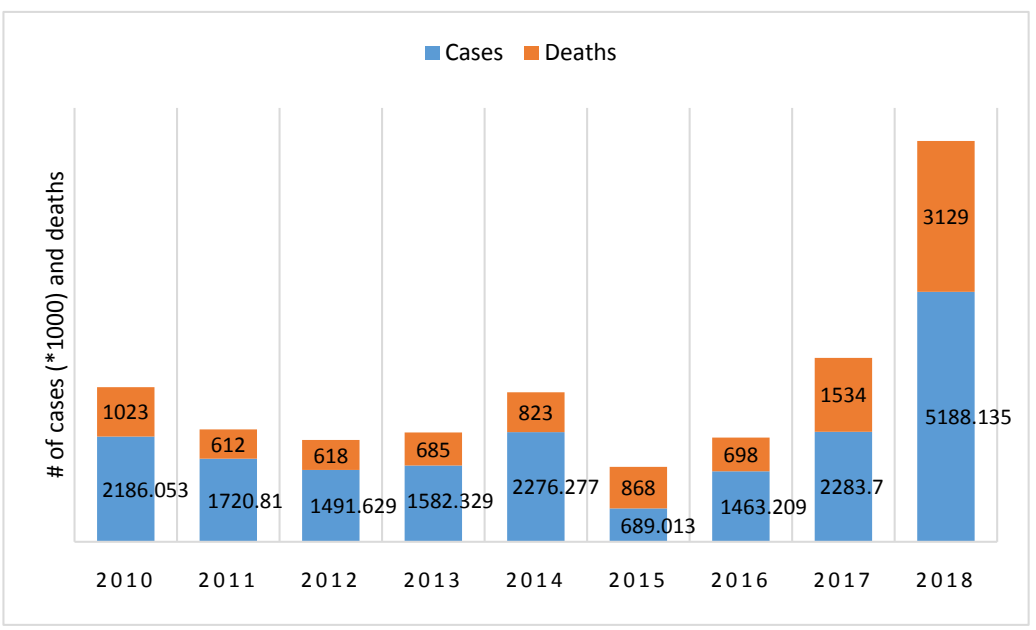

Figure 6. Reported malaria cases and deaths in Sudan, 2010-2018. 


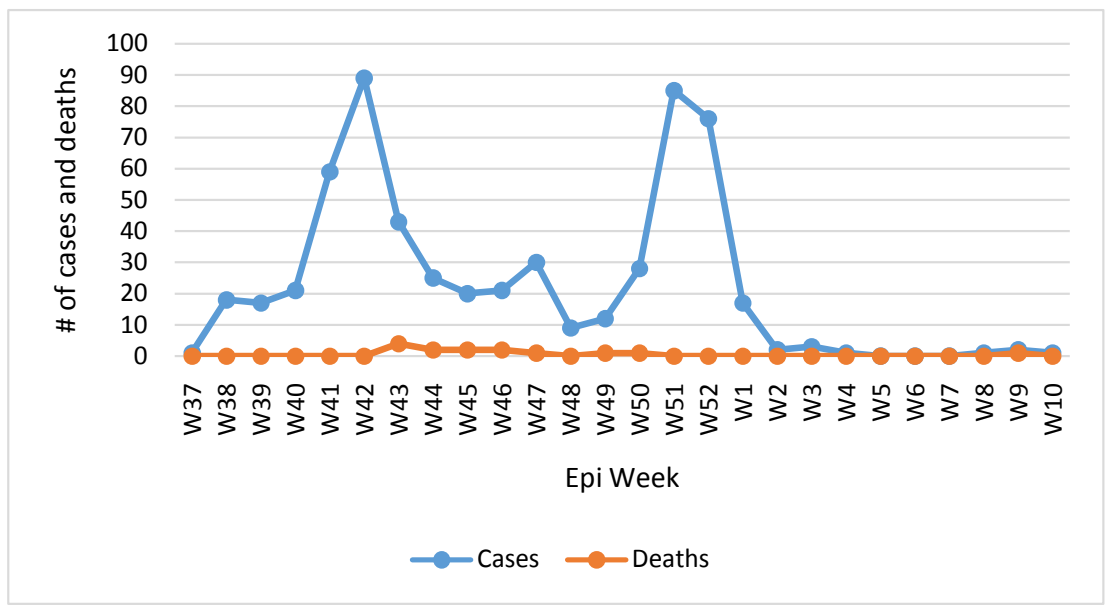

Figure 7. Rift Valley fever cases and deaths by Epi Weeks (W37-W52, 2019) (W1-W11, 2020).

The states of Darfur region were the most affected by the outbreak of these diseases in the country. This may be explained by several factors. First, the Darfur region experienced large mass internal displacement due to conflicts and violent events in the country since the beginning of the Darfur conflict in 2003. These factors resulted in a high degree of vulnerability to disease outbreaks in this region among all the states in the country. Second, people were living in unwarranted environments in different camps, and the health facilities in the displaced camps did not have the same response capacity as those in the cities. In addition, the preventive measures applied in the displaced societies were often not sustainable. One of these preventive measures is the immunization of people in this region. Therefore, it is necessary that the government develops a long-term plan to increase the coverage of immunization in the entire country and identify hotspots through surveillance.

More than 5560 cases were reported in Sudan in 2019 due to the outbreak of diseases. Women were found to be at a higher risk for all diseases, except River Valley fever (56\% for men vs. $44 \%$ for women). The age groups most affected by cholera, chikungunya, dengue, diphtheria, and River Valley fever were $\geq 45$ and 15 - 29 years, respectively. As shown in Table 1, the prevalence of the diseases among the western states (East Darfur, North Darfur, South Darfur, and West Darfur) was higher than that among the other states. This could be attributed to environmental factors such as floods and seasonal heavy rains as well as lack of effective vector control programs, in addition to the lack of vaccinations for children and adolescents.

The analysis of data showed that the states with the highest risk of cholera outbreak were Blue Nile, Sinnar, southeastern Sudan, bordering Ethiopia, and South Sudan (Table 1 Most of the cases were female (62\%), and $91 \%$ of the affected patients were aged $>5$ years. This outbreak occurred after the recent severe rainstorms and flooding in Sudan. Because the disease transmits via contaminated water and food, the public health practices of quarantine and vaccina- 
tion strategies are not sufficient to prevent and control cholera. Efforts should include progress in vaccination, access to safe drinking water, sanitary disposal of waste, disease detection, and case management [23].

The results of this study also showed that most of the chikungunya cases were reported from West Darfur state (71\%). The CFR was $2.05 \%$, and among all cases, females represented $64 \%$. The most affected age group was 15 - 29 years (35\%). The overall risk of chikungunya in the country was very high due to the presence of A. aegypti in most parts of the country and the availability of breeding sites due to rainy season, which favors the proliferation of the vector.

In Sudan, dengue fever outbreak has occurred since the 1900s, frequently gaining epidemic status mainly in eastern Sudan [17] [24] [25]. 2019 Dengue fever outbreak had spread to five states across the country due to the presence of suitable mosquito vectors in the country. In total, $53 \%$ of the affected patients were female and $93 \%$ were aged $>5$ years. Dengue fever was not explicitly treated; nevertheless, early diagnosis and access to adequate medical services reduced the fatality levels to $<1 \%$. Therefore, the government must implement urgent efforts for early detection of the disease and case management to help reduce deaths. Implementation of effective vector control measures is also critical to dengue prevention and control.

The results showed that the majority of diphtheria cases were from South Darfur states, in particular from one locality named Al Sunta (99\%), which could be explained by the lack of mobile immunization teams, in addition to the cold chain system that has been dysfunctional for the past 3 years. Notably, the cases reported among children aged under 5 years is $10 \%$, which is less compared with that in children aged 8 years (1979-1986), and 55.2\% of cases are reported among children aged under 5 years [26].

Our results indicated a progressive increase in the number of malaria cases reported across the country during the past 10 years. The number of deaths increased in 2018, reaching an abnormal number that had never been recorded in Sudan; it represented $94 \%$ of the number of deaths in the WHO Eastern Mediterranean Region (Afghanistan, Djibouti, Iran, Pakistan, Saudi Arabia, Somalia, Sudan, and Yemen). In 2019, the rainy season in Sudan was longer and more intense than normal. This resulted in the widespread presence of stagnant floodwaters contributing to the breeding of mosquitoes carrying the parasite and causing malaria. In 2019, malaria broke the epidemic threshold due to the sharp increase in the number of malaria cases compared with those of previous years. Most cases of disease outbreaks in 2019 were of malaria, accounting for $12.4 \%$ of cases, with a mortality rate of 0.0013 . In November 2019, approximately 250,000 cases of malaria were reported in Darfur, the most affected state, with the following distribution: South Darfur (110,000 cases), North Darfur (103,000 cases), and East Darfur (45,000 cases). The lack of drugs at primary health clinics is still the major problem in controlling malaria [11].

Analysis of data showed that the number of Rift Valley fever cases peaked 
around Week 42 in 2019, then declined, peaked again in Week 52, and then declined until it ended in Week 4 in 2020. Unlike other diseases, Rift Valley fever affected the River Nile state in the north of Sudan, Red Sea, Kassala, and Gadarif in eastern Sudan. As per historical records, River Nile state is the state that has most frequently experienced the outbreak of this disease [26].

This could be justified by the abundance of mosquitoes due to increased rainfall and flooding in the State [27].

\section{Limitation of the Study}

Due to political strikes and youth revolution in Sudan at the end of December 2019 and the beginning of 2020, the researcher finds a constraint for completeness of data regarding on malaria and cholera outbreak for the year 2019-2020. Therefore, the results reported herein should be considered in light of this limitation.

\section{Conclusions}

A major challenge for the prevention and control of diseases in Sudan is the limitation of response capacities of the public health sector. Furthermore, a highly inadequate research support restricts the provision of evidence for the arboviral epidemiology and dynamics of diseases in Sudan [1].

Due to the political and civil conflicts in the country, the capacity to prevent or control outbreaks has been insufficient. In contrast, disease outbreaks require effective monitoring and prevention strategies to mitigate potential outbreaks in due time. Effective prevention and control of diseases significantly depend on the improvement of vector-control efforts.

\section{Acknowledgements}

The author thanks Dr. Abdumageed Osman for his helpful discussions and critical revision of earlier versions of the manuscript, the author also thanks WHO, Sudan Office and FMOH, Sudan for providing him with data and reports for this study.

\section{Financial Support}

This research did not receive any specific grant from funding agencies in the public, commercial, or not-for-profit sectors.

\section{Availability of Data and Material}

The data supporting the results of this study are available upon request to the corresponding author.

\section{Conflicts of Interest}

The author declares no conflicts of interest regarding the publication of this 
paper.

\section{References}

[1] Ahmed, S.S., Soghaier, M.A., Mohammed, S., Khogali, H.S., Osman, M.M. and Abdalla A.M. (2016) Concomitant Outbreaks of Yellow Fever and Hepatitis E Virus in Darfur States, Sudan, 2012. The Journal of Infection in Developing Countries, 10, 24-29. https://doi.org/10.3855/jidc.6342

[2] Malik, A., Earhart, K., Mohareb, E., Saad, M., Saeed, M., Ageep A. and Soliman, A. (2011) Dengue Hemorrhagic Fever Outbreak in Children in Port Sudan. Journal of Infection and Public Health, 4, 1-6. https://doi.org/10.1016/j.jiph.2010.08.001

[3] Boccia, D., Guthmann, J.P., Klovstad, H., Hamid, N., Tatay, M. (2006) High Mortality Associated with an Outbreak of Hepatitis E among Displaced Persons in Darfur, Sudan. Clinical Infectious Diseases, 42, 1679-1684.

https://doi.org/10.1086/504322

[4] Saleh, A.S., Mohammed, K.A., Hassan, M.M., Bucci, T.J. and Meegan, J.M. (1981) Antibodies to Rift Valley Fever Virus in the Human Population of Sudan. Transactions of the Royal Society of Tropical Medicine and Hygiene, 75, 129-130. https://doi.org/10.1016/0035-9203(81)90039-0

[5] Watts, D.M., El-Tigani, A., Botros, B.A., Salib, A.W. and Olson, J.G., McCarthy, M. and Ksiazek, T.G. (1994) Arthropod-Borne Viral Infectious Associated with a Fever Outbreak in the Northern Province of Sudan. The American Journal of Tropical Medicine and Hygiene, 97, 228-230.

[6] Levy, B., Edholm, C., Gaoue, O., Kaondera-Shava, R., Kgosimore, M., Lenhart, S., et al. (2017) Modeling the Role of Public Health Education in Ebola Virus Disease Outbreaks in Sudan. Infectious Disease Modelling, 2, 323-340.

https://doi.org/10.1016/j.idm.2017.06.004

[7] Sulaiman, A.A., Elmadhoun, W.M., Noor, S.K., Almobarak, A.O., Bushara, S.O., et al. (2020) An Outbreak of Measles in Gold Miners in River Nile State, Sudan. Eastern Mediterranean Health Journal, 26, 152-160. https://doi.org/10.26719/2020.26.2.152

[8] Glatman-Freedman, A. and Nichols, K. (2012) The Effect of Social Determinants on Immunization Programs. Human Vaccines \& Immunotherapeutics, 8, 293-301. https://doi.org/10.4161/hv.19003

[9] Hussien, H. H. (2019) Malaria's Association with Climatic Variables and an Epidemic Early Warning System Using Historical Data from Gezira State, Sudan. $\mathrm{He}$ liyon, 5, e01375. https://doi.org/10.1016/j.heliyon.2019.e01375

[10] McCarthy, M.C., Haberberger, R.L., Salib, A.W., Soliman, B.A., El-Tigani, A., Khalid, I.O. and Watts, D.M. (1996) Evaluation of Arthropod-Borne Viruses and Other Infectious Disease Pathogens as the Causes of Febrile Illnesses in the Khartoum Province of Sudan. Journal of Medical Virology, 48, 141-146. https://doi.org/10.1002/(SICI)1096-9071(199602)48:2<141::AID-JMV4>3.0.CO;2-9

[11] World Health Organization (2019) Epidemic and Pandemic Prone Diseases. Outbreak update-Cholera in Sudan, 14 December 2019. World Health Organization. http://www.emro.who.int/pandemic-epidemic-diseases/cholera/outbreak-update-ch olera-in-sudan-14-december-2019.html

[12] Singal, A. (2017) Chikungunya and Skin: Current Perspective. Indian Dermatology Online Journal, 8, 307-309. https://doi.org/10.4103/idoj.IDOJ $93 \quad 17$

[13] Adam, A., Seidahmed, O.M.E., Weber, C., Schnierle, B., Schmidt-Chanasit, J., Reiche, S. and Jassoy, C. (2016) Low Seroprevalence Indicates Vulnerability of Eastern and Central Sudan to Infection with Chikungunya Virus. Vector Borne Zoo- 
notic Diseases, 16, 290-291. https://doi.org/10.1089/vbz.2015.1897

[14] Farnon, E.C., Gould, L.H., Griffith, K.S., Osman, M.S., et al. (2010) Household-Based Sero-Epidemiologic Survey after a Yellow Fever Epidemic, Sudan, 2005. The American Journal of Tropical Medicine and Hygiene, 82, 1146-1152.

https://doi.org/10.4269/ajtmh.2010.09-0105

[15] Salim, A.R. and Porterfield, J.S. (1973) A Serological Survey on Arbovirus Antibodies in the Sudan. Transactions of the Royal Society of Tropical Medicine and Hygiene, 67, 206-210. https://doi.org/10.1016/0035-9203(73)90145-4

[16] Allison, J.R., Hogue, A.L., Shafer, C.W. and Huntington, M.K. (2019) Infectious Disease: Mosquito-Borne Viral Illnesses. FP Essentials, 476, 11-17.

[17] Ahmed, A., Elduma, A., Magboul. B., Higazi, T. and Ali, Y. (2019) The First Outbreak of Dengue Fever in Greater Darfur, Western Sudan. Tropical Medicine and Infectious Disease, 4, 43. https://doi.org/10.3390/tropicalmed4010043

[18] Adler, N.R., Mahony, A. and Friedman, N.D. (2013) Diphtheria: Forgotten, but Not Gone. Internal Medicine Journal, 43, 206-210. https://doi.org/10.1111/imj.12049

[19] Carrillo, F. (2010) Learning to Recognize MALARIA. The Nurse Practitioner, 35, 38-42. https://doi.org/10.1097/01.NPR.0000375812.81771.ef

[20] Ibrahim, E.H., Taha, R., Ghramh, H.A. and Kilany, M. (2019) Development of Rift Valley Fever (RVF) Vaccine by Genetic Joining of the RVF-Glycoprotein Gn with the Strong Adjuvant Subunit B of Cholera Toxin (CTB) and Expression in Bacterial System. Saudi Journal of Biological Sciences, 26, 1676-1681. https://doi.org/10.1016/j.sjbs.2018.08.019

[21] Pratt, A.N., Bonnet, P., Jabbar, M., Ehui, S. and de Haan, C. (2005) Benefits and Costs of Compliance of Sanitary Regulations in Livestock Markets: The Case of Rift Valley fever in the Somali Region of Ethiopia. Research Report, AgEcon Search. https://ageconsearch.umn.edu/record/182867

[22] Wanyoike, F., Mtimet, N. and Bett, B (2019) Willingness to Pay for a Rift Valley Fever (RVF) Vaccine among Kenyan Cattle Producers. Preventive Veterinary Medicine, 171, Article ID: 104763. https://doi.org/10.1016/j.prevetmed.2019.104763

[23] Glass, R.I., Blake, P.A., Waldman, R.J, Claeson, M. and Pierce, N.F. (1991) Cholera in Africa: Lessons on Transmission and Control for Latin America. The Lancet, 338, 791-795. https://doi.org/10.1016/0140-6736(91)90673-D

[24] Soghaier, M.A., Himatt, S., Osman, K.E., Okoued, S.I., Seidahmed, O.E., et al. (2015) Cross-Sectional Community-Based Study of the Socio-Demographic Factors Associated with the Prevalence of Dengue in the Eastern Part of Sudan in 2011. BMC Public Health, 15, Article No. 558. https://doi.org/10.1186/s12889-015-1913-0

[25] Seidahmed, O.M.E., Hassan, S.A., Soghaier, M.A., Siam, H.A.M., Ahmed, F.T.A., Elkarsany, M.M. and Sulaiman, S.M. (2012) Spatial and Temporal Patterns of Dengue Transmission along a Red Sea Coastline: A Longitudinal Entomological and Serological Survey in Port Sudan City. PLoS Neglected Tropical Diseases, 6, e1821. https://doi.org/10.1371/journal.pntd.0001821

[26] Loevinsohn, B.P. (1990) The Changing Age Structure of Diphtheria Patients: Evidence for the Effectiveness of EPI in the Sudan. Bulletin of the World Health Organization, 68, 353-357.

[27] Hassan, O.A., Ahlm, C., Sang, R. and Evander, M. (2011) The 2007 Rift Valley Fever Outbreak in Sudan. PLoS Neglected Tropical Diseases, 5, e1229.

https://doi.org/10.1371/journal.pntd.0001229 